\title{
Age Specificity in General and Rehabilitation Medical Services in Children With Cerebral Palsy
}

\author{
Dong-A Kim, MD ${ }^{1}$, Hyun-Sook Hong, $\mathrm{PhD}^{2}$, Hee-Yeon Lee, $\mathrm{MPH}^{2}$, \\ Hye-Sun Lee, $\mathrm{MD}^{1}$, Min-Sung Kang, $\mathrm{MD}^{1}$ \\ ${ }^{1}$ Department of Rehabilitation Medicine, National Rehabilitation Center, Seoul; \\ ${ }^{2}$ National Rehabilitation Research Institute, Seoul, Korea
}

Objective To review the medical utilization in children with cerebral palsy according to age and discern particularities

Methods From January 2007 to December 2007, 10,659 children and adolescents between 1 and 18 years of age who had filed national insurance claims for a diagnosis of cerebral palsy were selected. Age was chosen as an independent variable, and the population was categorized into specific age groups to verify any differences in medical service utilization. Admission duration to rehabilitation, number of visits to rehabilitation outpatient clinics, numbers of admission dates and outpatient clinic visits for general medical services, number of rehabilitation utilizations, and type of rehabilitations treatment were selected as dependent variables. One-way ANOVA was used for statistical evaluation, and analysis was done with SAS software.

Results In general medical use, adolescences diagnosed with cerebral palsy had the highest mean admission duration $(\mathrm{p}<0.001)$. The mean visit day to outpatient clinics for general medical services was highest for infants $(\mathrm{p}<0.001)$. In rehabilitation treatment, infants diagnosed with cerebral palsy had the highest mean admission duration $(\mathrm{p}<0.001)$. The mean visit day to outpatient clinics for rehabilitation treatment was highest for infants $(\mathrm{p}<0.001)$.

Conclusion Significant differences in use of general and rehabilitation medical services among pediatric age groups with cerebral palsy were evident. This implies that particular attention is necessary when setting up a national medical care policy for patient with cerebral palsy.

Keywords Cerebral palsy, Age, Cost, Visit, Treatment

Received April 10, 2014; Accepted July 23, 2014

Corresponding author: Min-Sung Kang

Department of Rehabilitation Medicine, National Rehabilitation Center, 58 Samgaksan-ro, Gangbuk-gu, Seoul 142-884, Korea

Tel: +82-2-901-1634, Fax: +82-2-902-3835, E-mail: ronaldo77@daum.net

(c) This is an open-access article distributed under the terms of the Creative Commons Attribution Non-Commercial License (http://creativecommons. org/licenses/by-nc/3.0) which permits unrestricted noncommercial use, distribution, and reproduction in any medium, provided the original work is properly cited.

Copyright $\odot 2014$ by Korean Academy of Rehabilitation Medicine

\section{INTRODUCTION}

Cerebral palsy (CP) denotes a group of diseases characterized by non-persistent damage to the brain of infants or neonates, which results in permanent movement and posture disabilities. These disabilities from CP markedly reduce the level of activity. Other associated problems include sensory, cognition, communication and perception impairments; behavioral disability; seizure; and musculoskeletal involvement [1]. 
The prevalence of CP in the United States in 2002 was 3.6 per 1,000 neonates [2]. A domestic study that investigated 5 -year-old children from 2004 to 2008 reported a CP prevalence of 2.6 per 1,000 children [3]. In South Korea, CP prevalence has been rising, in part due to the improved survival of premature infants with medical comorbidities [3-6]. In the United States, CP increased in prevalence by $20 \%$ from 1960 to 1980 [4]. An increase was chronicled in Sweden from $1.9 \%$ in the 1950 s to $2.2 \%$ in the 1980 s [7].

Disability from CP in a newborn places a severe burden on the patients in particular and society more generally. Treatment of the permanent impairments necessitates constant effort and support [8]. Early treatment is imperative since adaptability to brain lesion and brain plasticity in children is considerably higher than those in adults [9].

Despite the importance of early diagnosis and treatment, in clinical settings delays occur. Moreover, treatment plans may not be differentiated or individualized according to age-related specificity and other considerations. Thus, to manage $\mathrm{CP}$ patients more effectively and actively, national attention and adequate financial support should be provided. Policy making by the national health authority and improvements in social support are needed, and collection of basic data, such as the age of CP patients and their use of medical services are essential to analyze the current situation.

Such data is scant in South Korea. Several studies on CP patients have been published, but these featured limited sample size and inadequate results or conclusions due to undifferentiated patient characteristics, such as age.

Presently, the Health Insurance Review and Assessment Service (HIRA) service database on medical service claims was exploited to investigate age-specific usage of general and rehabilitation medical services by $\mathrm{CP}$ patients.

\section{MATERIALS AND METHODS}

\section{Subjects}

Our study included any infants or adolescents aged 1-18 years whose medical service providers had declared claims at least once with the diagnoses of $\mathrm{CP}$ and hemiplegia (G80-81) between January 2007 and December 2007. Annual claims of 10,659 subjects were reviewed using HIRA records. There were 6,247 male $(58.6 \%)$ and 4,412 female patients $(41.4 \%)$. There were $3,343(31.4 \%)$ patients 3-6 years of age, which was the largest age group, followed by $7-12$ years of age $(n=3,264,30.6 \%), 1-2$ years $(n=2,438,22.9 \%)$, and $13-18$ years of age $(n=1,614$, $15.1 \%)$. Concerning the types of medical insurance, $74.9 \%$ of patients received benefits from national health insurance and medical aid provided for the services in $25.1 \%$ of patients (Table 1). Extent of rehabilitation therapy was defined as claims declared with medical procedure codes by the service providers that fall into chapter seven (Medical Procedure Fee) and clause three (Fee for Special Rehabilitation Therapy) of National Health Insurance Services statute on paying medical care expenses for therapeutic procedures. Exempting rehabilitation services, the rest were considered as general care claimed for provision of general medical needs of the $\mathrm{CP}$ patients.

\section{Statistical analysis}

Age was treated as an independent variable and was categorized into four groups: infant (1-2 years of age), preschool (3-6 years of age), school (7-12 years of age), and adolescent (13-18 years of age) to generate ordinal variables for verification of any age-related differences in medical service use among CP patients. Dependent variables were duration of admission or number of visits to outpatient clinics for general medical care, duration of admission or number of visits to outpatient clinics for the

Table 1. Characteristics of participants

\begin{tabular}{lrrrrr}
\hline \multirow{2}{*}{ Age $(\mathbf{y r})$} & \multicolumn{2}{c}{ Gender } & \multicolumn{2}{c}{ Type of health insurance } & \multirow{2}{*}{ Total } \\
\cline { 2 - 5 } \cline { 5 - 6 } & \multicolumn{1}{c}{ Male } & \multicolumn{1}{c}{ Female } & Health insurance & Medical care assistance & \\
\hline $1-2$ & $1,396(57.3)$ & $1,042(42.7)$ & $2,014(82.6)$ & $424(17.4)$ & $2,438(22.9)$ \\
$3-6$ & $1,907(57.0)$ & $1,436(43.0)$ & $2,444(73.1)$ & $899(26.9)$ & $3,343(31.4)$ \\
$7-12$ & $1,934(59.3)$ & $1,330(40.8)$ & $2,327(71.3)$ & $937(28.7)$ & $3,264(30.6)$ \\
$13-18$ & $1,010(62.6)$ & $604(37.4)$ & $1,198(74.2)$ & $416(25.8)$ & $1,614(15.1)$ \\
Total & $6,247(58.6)$ & $4,412(41.4)$ & $7,983(74.9)$ & $2,676(25.1)$ & 10,659 \\
\hline
\end{tabular}

Values are presented as number (\%). 
purpose of rehabilitation therapy and frequency/types of rehabilitation therapy. For statistical analysis, one-way ANOVA was performed to find any significant differences among the group in the use of medical service. A $p<0.05$ was considered statistically significant. All statistical analyses were executed with SAS ver. 9.1 software (SAS Institute Inc., Cary, NC, USA).

\section{RESULTS}

Mean duration of admission and mean dates of visits to outpatient clinics for general medical care and rehabilitation

For general medical care, mean duration of admission per patient was highest in the adolescent group (25.0 days) followed by school age group (15.8 days), infants (12.8 days), and the preschool age group (10.7 days). The differences were statistically significant $(\mathrm{p}<0.001)$. Mean dates of visits to general outpatient clinics was highest in the infant group (35.3 days), followed by the preschool age group (24.8 days). The school age and adolescent groups had mean visits of 15.7 and 11.8 days, respectively. The differences were significant $(\mathrm{p}<0.001)$ (Table 2).

Concerning rehabilitation therapy, the mean duration of admission for rehabilitation was highest in the infant group (61.3 days). The mean duration for the preschool, adolescent, and school age groups was 46.2, 43.4, and 32.2 days, respectively, which were all statistically significant (all $\mathrm{p}<0.001$ ). The infant group also displayed the highest mean dates of visits to rehabilitation outpatient clinics (61.6 days), followed by the preschool age group (60.0 days), school age group (41.7 days), and the adolescent group (23.0 days). Statistical significance was also shown in the mean numbers among the four groups (all $\mathrm{p}<0.001$ ) (Table 2).

Medical expenses for services during admission and visits to outpatient clinics to receive general medical care and rehabilitation

For CP patients receiving general medical care, mean medical expense during admission per person was highest in adolescents $(4,196,112$ Korean won [KRW]), followed by the school age group $(2,994,804 \mathrm{KRW})$, infant group $(2,242,900 \mathrm{KRW})$, and preschool age group $(1,908,927 \mathrm{KRW})$. The differences were significant $(\mathrm{p}<$ $0.001)$. Mean cost for general medical care in outpatient clinics was highest in the infant group (635,469 KRW). The expense for the preschool, school, and adolescent age groups was 440,871, 368,008, and 345,319 KRW, respectively $(\mathrm{p}<0.001)$ (Table 3$)$. However, comparison of mean costs of admission and outpatient clinic revealed no statistical significance.

For mean individual expense of admission for rehabilitation in CP patients, the infant group's charge was highest $(6,939,425 \mathrm{KRW})$, followed by the preschool group

Table 3. Mean hospital cost (unit, Korean won) for general medical treatment and rehabilitation treatment

\begin{tabular}{|c|c|c|c|c|}
\hline \multirow{2}{*}{$\begin{array}{l}\text { Age } \\
\text { (yr) }\end{array}$} & \multicolumn{2}{|c|}{$\begin{array}{l}\text { General medical } \\
\text { treatment }\end{array}$} & \multicolumn{2}{|c|}{$\begin{array}{c}\text { Rehabilitation } \\
\text { treatment }\end{array}$} \\
\hline & Inpatient & Outpatient & Inpatient & Outpatient \\
\hline $1-2$ & $2,242,900$ & 635,469 & $6,939,425$ & $2,258,944$ \\
\hline $3-6$ & $1,908,927$ & 440,871 & $5,814,419$ & $2,199,955$ \\
\hline $7-12$ & $2,994,804$ & 368,008 & $4,464,442$ & $1,468,875$ \\
\hline $13-18$ & $4,196,112$ & 345,319 & $5,667,179$ & 824,067 \\
\hline Total & $2,444,121$ & 451,020 & $5,867,199$ & $1,783,340$ \\
\hline $\mathrm{p}$-value & $<0.001$ & $<0.001$ & $<0.001$ & $<0.001$ \\
\hline
\end{tabular}

Table 2. Mean admission duration and mean outpatient visit day for general medical treatment and rehabilitation treatment

\begin{tabular}{|c|c|c|c|c|}
\hline \multirow{2}{*}{$\begin{array}{l}\text { Age } \\
\text { (yr) }\end{array}$} & \multicolumn{2}{|c|}{ General medical treatment } & \multicolumn{2}{|c|}{ Rehabilitation treatment } \\
\hline & Mean admission duration & Mean outpatient visit day & Mean admission duration & Mean outpatient visit day \\
\hline $1-2$ & $12.8 \pm 17.1$ & $35.3 \pm 22.2$ & $61.3 \pm 67.9$ & $61.6 \pm 60.9$ \\
\hline $3-6$ & $10.7 \pm 21.3$ & $24.8 \pm 21.3$ & $46.2 \pm 58.0$ & $60.0 \pm 61.9$ \\
\hline $7-12$ & $15.8 \pm 35.6$ & $15.7 \pm 18.5$ & $32.2 \pm 54.8$ & $41.7 \pm 50.9$ \\
\hline $13-18$ & $25.0 \pm 36.7$ & $11.8 \pm 15.1$ & $43.4 \pm 67.7$ & $23.0 \pm 38.5$ \\
\hline Total & $13.8 \pm 25.3$ & $22.7 \pm 21.6$ & $47.7 \pm 62.6$ & $49.2 \pm 57.1$ \\
\hline $\mathrm{p}$-value & $<0.001$ & $<0.001$ & $<0.001$ & $<0.001$ \\
\hline
\end{tabular}

Values are presented as mean \pm standard deviation. 
Table 4. Mean number of inpatient rehabilitation treatmentt

\begin{tabular}{lrrrrrrrr}
\hline Age (yr) & NDT & M\&T & Special OT & ADL & FES & Gait & Etc. & p-value \\
\hline $1-2$ & 23.17 & 17.26 & 15.24 & 12.99 & 7.86 & 4.93 & 3.64 & $<0.001$ \\
$3-6$ & 13.59 & 7.95 & 9.38 & 7.86 & 4.91 & 5.65 & 2.03 & $<0.001$ \\
$7-12$ & 3.88 & 2.44 & 2.65 & 2.21 & 1.43 & 1.42 & 0.70 & $<0.001$ \\
$13-18$ & 3.98 & 1.96 & 2.32 & 2.53 & 1.95 & 2.46 & 1.58 & $<0.001$ \\
\hline
\end{tabular}

NDT, neurodevelopmental therapy; M\&T, mat and transfer therapy; Special OT, special occupational therapy; ADL, activities of day living therapy; FES, functional electrical stimulation therapy; Gait, gait therapy.

Table 5. Mean number of inpatient rehabilitation treatmentt

\begin{tabular}{lcrcccccc}
\hline Age (yr) & NDT & M\&T & Special OT & ADL & FES & Gait & Etc. & p-value \\
\hline $1-2$ & 44.97 & 30.13 & 21.32 & 21.84 & 5.23 & 5.64 & 5.86 & $<0.001$ \\
$3-6$ & 38.65 & 21.79 & 23.60 & 25.05 & 4.99 & 11.68 & 8.33 & $<0.001$ \\
\hline $7-12$ & 24.65 & 12.67 & 13.42 & 14.57 & 4.01 & 8.87 & 6.47 & $<0.001$ \\
$13-18$ & 11.90 & 5.98 & 5.02 & 6.34 & 2.88 & 5.05 & 4.34 & $<0.001$ \\
\hline
\end{tabular}

NDT, neurodevelopmental therapy; M\&T, mat and transfer therapy; Special OT, special occupational therapy; ADL, activities of day living therapy; FES, functional electrical stimulation therapy; Gait, gait therapy.

(5,814,419 KRW), adolescent group (5,667,179 KRW), and school age group $(4,464,442 \mathrm{KRW})(\mathrm{p}<0.001)$.

Mean cost for outpatient based rehabilitation therapy was highest in the infant group $(2,258,944 \mathrm{KRW})$, followed by the preschool, school and adolescent age group $(2,199,955,1,468,875$, and 824,067 KRW, respectively). The differences were statistically significant $(\mathrm{p}<0.001)$ (Table 3). However, no statistical difference was evident between the mean expenses per person of admission and visits to outpatient clinics for rehabilitation therapy.

Age-specific usage of rehabilitation for the various therapies

When admitted to a hospital, neurodevelopment treatment was used most frequently, with statistical significance evident in all four groups (all $\mathrm{p}<0.001$ ). In the infant group, the next most commonly used rehabilitation therapy was mat training. In the preschool and school age groups, the second most common therapy was special occupational therapy. Therapy concerning activities of daily living was the most frequently prescribed treatment after neurodevelopment treatment. All these therapies of the four groups were significantly different (Table 4).

For therapies in the outpatient setting, neurodevelopment treatment was the most frequently prescribed plan, and the mean number of the use per person had significant difference among the four groups $(p<0.001)$.
In the infant group, mat training was the second most prescribed outpatient treatment, but in outpatient clinics activities of daily living therapy was second most common in the preschool, school and adolescent age groups after neurodevelopment treatment. These mean frequencies per person were also significantly different in all four groups (Table 5).

\section{DISCUSSION}

To treat $\mathrm{CP}$, it is important to plan a specific treatment schedule in relation to different progresses of growth and development that are characteristic to various age groups, and the treatment should start at the earliest possible moment. This logic is based on potentially high brain plasticity in children and the theory of critical period. The theory states that without proper stimulation from surroundings during the limited time of developmental process in children, a child may lose time that is crucial to learn specific behaviors important for future development [10].

Recently, there have been reports with good outcomes which the studies assert the importance of early diagnosis and treatment in CP. The studies suggest that patients who had received treatment prior to 6 months after birth showed faster motor development than those who started receiving the treatment 6 months after birth $[11,12]$. In 
addition, the studies also advocated that early treatment for disabled children including $\mathrm{CP}$ patients has an effect of reducing psychological stress of family members, resulting in a positive functional prognosis of the children $[13,14]$.

Although it is imperative to start the CP treatment at the earliest possible time, great attention must also be put on a specific treatment process in relation to particular age. Delay in initiating treatment and lack of systematic method in accordance with age may result in secondary problems, such as joint contracture, muscle shortening, and deformity, which in turn reduce treatment efficacy and impede functional improvement that could otherwise be enhanced with a proper treatment strategy $[10,15,16]$.

In CP patients, secondary deformation and degenerative change of the musculoskeletal system becomes evident considerably earlier in life. The deformation and degeneration produce pain and fatigue in the musculoskeletal system and regressive gait function. Progressive contracture and degeneration of joints and amplifying pain and fatigue in musculoskeletal system gradually limit the distance and time that the patients can move, making them adopt a more sedentary lifestyle. Without an adequate level of daily activity, these patients may gain more weight and, together with the more sedentary lifestyle, this can affect further contracture of joints and muscle weakness. Eventually, about one-fourth of CP children lose the ability of walking when they become adults $[10,17-20]$. Therefore, noticing the changes of musculoskeletal system at the earliest and initiating treatment accordingly are significant to prevent or at least to slow the progress to worsening level of activity in these patients. In addition to musculoskeletal disability, urination, and defecation problems like neurogenic bladder and constipation are also commonly encountered problems in this patient group. These must be properly assessed and should be managed adequately and quickly [21-23].

Treating CP children comprises various methods including exercise therapy (kinesitherapy), electric stimulation therapy, constraint therapy, medication, and surgery. Among them, the injection of botulinum toxin administration at $\geq 2$ years of age reduces spasticity and involuntary movement [24]. To alleviate spasticity, posterior rhizotomy is performed as a surgical measure, and it is reported to produce better improvement in function of joints when performed before the age of 5 years [16]. In addition, a combination of posterior rhizotomy and exercise therapy is far more effective in reducing spasticity and improving the function than exercise therapy alone [25]. To relieve joint contracture, between 4 and 7 years of age is considered an ideal period to perform orthopedic interventions, since any surgery prior to this time frame may increase the recurrence of joint contracture even after a surgery [26].

This study found that the adolescent group had the longest duration of admission per person for general medical care of CP. As the patients age, they develop more musculoskeletal problems resulting from secondary deformation or degeneration, pain, neurogenic bladder, osteoporosis, and other medical problems related to CP. Treatment of these consequences may contribute the long-term admission in this particular group [9,2729]. Presently, the number of visits to outpatient clinic for general medical purpose was highest in the infant group. CP patients have swallowing difficulty and postural impairment that reduces dietary intake and results in abnormal gastrointestinal tract motility, which in turn it may lead to nutritional imbalance [30]. In addition, dysfunction in synchronizing respiratory muscle, reduced coughing ability, more frequent incidences of aspiration due to swallowing difficulty, and gastroesophageal reflux may increase the risk of respiratory diseases [31].

In this study, duration of admission to receive rehabilitation was longest in the infant group. The reason for this outcome is believed to be recent advances in the early diagnosis of $\mathrm{CP}$; diagnosis in infancy leads to more admission and early initiation of treatment. Also, the number of visits to a rehabilitation outpatient clinic was also most frequent in the infant group; recent progress in early diagnosis of CP [10] may have contributed this outcome.

The age-specific differences shown in mean costs of admission and visit to outpatient clinic for general and rehabilitation care is likely due to varying durations of admission and number of visits to outpatient clinics found among different age groups.

Among various rehabilitation therapies received during admission and at outpatient clinics, neurodevelopment treatment was the most frequently prescribed therapy for the infant group followed by mat training. In the adolescent group, neurodevelopment treatment was also the most frequently given therapy, but the second most 
prescribed therapy was training for daily activities. This difference between the two groups is considered to originate from the different developmental stages.

Our study is meaningful since it is first study making investigation and analysis on age-specific usage of general medical care and rehabilitation in $\mathrm{CP}$ patients. However, there are several limitations. First, since the study is based on HIRA data, amount of claims that are not covered by national health insurance and information on treatments that are performed outside of hospital were not included. Second, only CP patients were studied and no analysis was performed on patients with brain lesions from traumatic and congenital origins. Third, the current situation of CP patients' age-specific usage in general medical care was studied in this study, but our study lacked analysis of specific conditions among the patients that had incited the need for the care. Further studies on the frequency of particular diseases or diseases requiring high treatment cost are necessary. Fourth, we included diagnostic codes G81 (hemiplegia) and G80 (CP). This was done to include all $\mathrm{CP}$ patients whose diagnosis has been recorded as G81 by an attending physician, since the code is frequently used for CP children whose cause of the palsy are hemorrhage after birth. Attending physicians sometimes assign these conditions as G81 rather than G80. However, it is possible that not all patients with the code of G81 have CP, and our study may contain some improper samples. In addition, the diagnoses were based on data of HIRA, and since the diagnoses were not matched with diagnoses in each patient's medical records there is possible incongruence in true nature of patient's diagnosis. Fifth, medical costs of general care were defined as the amount of total claim subtracted by the claims for rehabilitation therapies. However this computation does not allow the differentiation between costs related to $\mathrm{CP}$ and costs related to other general cares. Finally, we did not investigate factors like gender and type of health insurances that a patient has joined. Future studies including these factors may provide some interesting outcomes on CP patients' tendency or situation in medical services usage in accordance to the factors.

In conclusion, we performed a cross-sectional study on age-specific usage of medical service in patients with the diagnosis of CP during the year 2007. For general medical care in CP patients, mean duration of admission per person was significantly higher in the adolescent age group, and mean dates of visits to outpatient clinics was significantly greater in the infant group. Individual mean duration of admission and mean visits to outpatient clinic in CP patients for rehabilitation care was significantly greater in the infant group. The findings confirm that $\mathrm{CP}$ patients in each age group have various durations of receiving general and rehabilitation cares, and the authors expect that the data will have significant implication to improve conditions of medical services in these patients. Future studies benefit from the consideration of gender and types of health insurance.

\section{CONFLICT OF INTEREST}

No potential conflict of interest relevant to this article was reported.

\section{REFERENCES}

1. Rosenbaum P, Paneth N, Leviton A, Goldstein M, Bax $M$, Damiano D, et al. A report: the definition and classification of cerebral palsy April 2006. Dev Med Child Neurol Suppl 2007;109:8-14.

2. Yeargin-Allsopp M, Van Naarden Braun K, Doernberg NS, Benedict RE, Kirby RS, Durkin MS. Prevalence of cerebral palsy in 8-year-old children in three areas of the United States in 2002: a multisite collaboration. Pediatrics 2008;121:547-54.

3. Park MS, Kim SJ, Chung CY, Kwon DG, Choi IH, Lee KM. Prevalence and lifetime healthcare cost of cerebral palsy in South Korea. Health Policy 2011;100:2348.

4. Bhushan V, Paneth N, Kiely JL. Impact of improved survival of very low birth weight infants on recent secular trends in the prevalence of cerebral palsy. Pediatrics 1993;91:1094-100.

5. Dennis J, Matthews PW. Cerebral palsy. In: Molnar GE, Alexander MA, editors. Pediatric rehabilitation. 3rd ed. Philadelphia: Hanley \& Belfus; 1999. p. 193217.

6. Cummins SK, Nelson KB, Grether JK, Velie EM. Cerebral palsy in four northern California counties, births 1983 through 1985. J Pediatr 1993;123:230-7.

7. Hagberg B, Hagberg G, Olow I. The changing panorama of cerebral palsy in Sweden. VI. Prevalence and origin during the birth year period 1983-1986. Acta 
Paediatr 1993;82:387-93.

8. Kim SJ, Lee EH, Lee SH, Park BK, Sung IY, Na JK. Survey of the demands of the parents of children with cerebral palsy. J Korean Acad Rehabil Med 2000;24:1070-8.

9. Holt RL, Mikati MA. Care for child development: basic science rationale and effects of interventions. Pediatr Neurol 2011;44:239-53.

10. Sung IY, Shin YB, Park SS. Clinical feature and treatment of cerebral palsy. In: Sung IY, editor. Pediatric rehabilitation. 2nd ed. Seoul: Koonja; 2013. p. 383416.

11. Park CI, Park ES, Shin JC, Kim SW, Choi EH. Early treatment effect in children with cerebral palsy and delayed development. J Korean Acad Rehabil Med 1999;23:1127-33.

12. Hayashi M. The effect of early treatment for children with cerebral palsy in cooperation with city health welfare offices. No To Hattatsu 1995;27:480-6.

13. Pain H. Coping with a child with disabilities from the parents' perspective: the function of information. Child Care Health Dev 1999;25:299-312.

14. Palmer FB, Shapiro BK, Wachtel RC, Allen MC, Hiller JE, Harryman SE, et al. The effects of physical therapy on cerebral palsy: a controlled trial in infants with spastic diplegia. N Engl J Med 1988;318:803-8.

15.Zonta MB, Bruck I, Puppi M, Muzzolon S, Neto Ade C, Coutinho dos Santos LH. Effects of early spasticity treatment on children with hemiplegic cerebral palsy: a preliminary study. Arq Neuropsiquiatr 2013;71:45361.

16. Kim DS, Choi JU, Yang KH, Park CI. Selective posterior rhizotomy in children with cerebral palsy: a 10-year experience. Childs Nerv Syst 2001;17:556-62.

17. Andersson C, Mattsson E. Adults with cerebral palsy: a survey describing problems, needs, and resources, with special emphasis on locomotion. Dev Med Child Neurol 2001;43:76-82.

18. Opheim A, Jahnsen R, Olsson E, Stanghelle JK. Walking function, pain, and fatigue in adults with cerebral palsy: a 7-year follow-up study. Dev Med Child Neurol 2009;51:381-8.

19. Jahnsen R, Villien L, Aamodt G, Stanghelle JK, Holm I. Musculoskeletal pain in adults with cerebral palsy compared with the general population. J Rehabil Med 2004;36:78-84.
20. Jahnsen R, Villien L, Stanghelle JK, Holm I. Fatigue in adults with cerebral palsy in Norway compared with the general population. Dev Med Child Neurol 2003;45:296-303.

21. Murphy KP, Boutin SA, Ide KR. Cerebral palsy, neurogenic bladder, and outcomes of lifetime care. Dev Med Child Neurol 2012;54:945-50.

22. Veugelers R, Benninga MA, Calis EA, Willemsen SP, Evenhuis H, Tibboel D, et al. Prevalence and clinical presentation of constipation in children with severe generalized cerebral palsy. Dev Med Child Neurol 2010;52:e216-21.

23. Sheridan KJ. Osteoporosis in adults with cerebral palsy. Dev Med Child Neurol 2009;51 Suppl 4:38-51.

24. Simpson DM, Gracies JM, Graham HK, Miyasaki JM, Naumann M, Russman B, et al. Assessment: Botulinum neurotoxin for the treatment of spasticity (an evidence-based review): report of the Therapeutics and Technology Assessment Subcommittee of the American Academy of Neurology. Neurology 2008;70:1691-8.

25. McLaughlin J, Bjornson K, Temkin N, Steinbok P, Wright V, Reiner A, et al. Selective dorsal rhizotomy: meta-analysis of three randomized controlled trials. Dev Med Child Neurol 2002;44:17-25.

26. Woo R. Spasticity: orthopedic perspective. J Child Neurol 2001;16:47-53.

27. Parkinson KN, Gibson L, Dickinson HO, Colver AF. Pain in children with cerebral palsy: a cross-sectional multicentre European study. Acta Paediatr 2010; 99:446-51.

28. Ramstad K, Jahnsen R, Skjeldal OH, Diseth TH. Characteristics of recurrent musculoskeletal pain in children with cerebral palsy aged 8 to 18 years. Dev Med Child Neurol 2011;53:1013-8.

29. Henderson RC, Kairalla JA, Barrington JW, Abbas A, Stevenson RD. Longitudinal changes in bone density in children and adolescents with moderate to severe cerebral palsy. J Pediatr 2005;146:769-75.

30. Kim SJ. Cerebral palsy. J Korean Acad Rehabil Med 2000;24:809-16.

31. Savage K, Kritas S, Schwarzer A, Davidson G, Omari T. Whey- vs casein-based enteral formula and gastrointestinal function in children with cerebral palsy. JPEN J Parenter Enteral Nutr 2012;36(1 Suppl):118S-23S. 